* Doutorado em Direito pela Pontifícia Universidade Católica de São Paulo, Brasil. Professora associada da Universidade Estadual de Londrina. Docente dos cursos de graduação, especialização e mestrado em Direito. E-mail: lobomuniz@gmail.com

** Mestranda em Direito Negocial pela Universidade Estadual de Londrina. Bolsista CAPES. E-mail: glauciatorres2@gmail.com

\section{Da livre iniciativa e da confiança na relação empresa e consumidor}

\author{
FrEE ENTERPRISE AND CONFIDENCE IN RELATION \\ COMPANY AND CONSUMER \\ * Glaucia Cardoso Teixeira Torres \\ ** Tânia Lobo Muniz
}

Resumo: A presente reflexão tem por objetivo fazer uma análise da livre iniciativa em relação ao consumidor. Para tanto, a partir da sociedade feudal, busca-se apontar a relação do homem com o comércio assinalando sob qual contexto surgiram os valores livre-iniciativa e defesa do consumidor. Assinala, ainda, como se deu a positivação de tais institutos no ordenamento jurídico brasileiro para, ao final, fazer uma breve análise acerca da ética empresarial que elencou o valor confiança entre empresa e sociedade ao patamar de capital intangível das empresas.

Palavras-chave: Livre-iniciativa; Proteção do consumidor; Confiança; Empresa.

Abstract: This reflection aims to analyze the free enterprise in relation to consumer since his advent to the contemporary. For this it will be done a historical retrospect of man's relationship with trade to identify under what context emerged the values, free enterprise and consumer protection. It will be point how was the affirmations of such institutes in the Brazilian legal system to the end to make a brief analysis about business ethics that has listed the value of trust between business and society to the intangible capital level of companies.

Keywords: Free enterprise; Consumer protection; Confidence; Company. 


\section{INTRODUÇÃO}

Desde a mais remota antiguidade, o comércio aparece entre as atividades humanas. Inicialmente realizado por meio de trocas, passou progressivamente a empregar moeda em sua realização. Com a implementação das relações comerciais, aumento populacional e a expansão do número de cidades, o comércio foi impulsionado, passando a consistir em real possibilidade de ascensão social para os camponeses do sistema feudal.

Posteriormente, o liberalismo clássico apresentou-se como filosofia contrária ao mercantilismo vigente. Os liberais clamavam por liberdade nas relações comerciais e pelo direito de propriedade em toda sua plenitude. Nesse contexto foi forjado o valor livre iniciativa como desdobramento da propalada liberdade.

A partir dessa constatação, faz-se uma análise da relação entre a livre iniciativa e o consumidor, buscando-se o advento do princípio da livre-iniciativa bem como da proteção do consumidor. Para tanto, faz-se uma retrospectiva do liberalismo clássico e do intervencionismo estatal na ordem econômica, apontando-se a positivação de tais princípios no ordenamento jurídico brasileiro e seu status na constituição federal vigente.

Ao final, será feita uma análise à luz da contemporaneidade da relação entre empresa e consumidor e de como se deu a passagem de uma visão meramente utilitarista em relação ao consumidor ao estabelecimento da confiança entre consumidor e empresa como capital intangível destas.

\section{DA EXPANSÃO DO COMÉRCIO À LIVRE-INICIATIVA}

Na Idade Média, nos primórdios da sociedade feudal, as terras agrícolas da Europa Ocidental e central estavam fragmentadas em áreas conhecidas como feudos. Divididas em duas partes, uma pertencente ao senhor feudal, cultivada apenas para ele, e outra repartida entre inúmeros camponeses, rendeiros que trabalhavam arduamente em suas faixas de terra. Além disso, dois ou três dias por semana, tinham o dever de trabalhar gratuitamente nas terras do senhor. A posse da terra não concedia ao camponês o direito de trabalhar nela da maneira como entendesse ser melhor, sendo imprescindível a observação de regras impostas pelo senhor feudal, sob pena de perda da posse da terra. $\mathrm{O}$ suserano detinha poder e preferência de diversas formas. Quando sua propriedade tivesse que ser arada, semeada ou ceifada, os camponeses deveriam 
priorizar estas ações em detrimento do trabalho a ser realizado em sua própria terra. A ideia de liberdade de iniciativa dos camponeses era, portanto, muito limitada.

A vida econômica era desempenhada quase sem utilização da moeda. Havia uma economia de consumo, em que cada aldeia feudal era praticamente autossuficiente, quase nada era comprado. Um pouco de sal, talvez, e algum ferro. Quanto ao restante dos bens necessários à sobrevivência, quase todos eram obtidos no próprio feudo. Certamente, estabeleciam-se relações de troca, mas, poucas delas utilizavam-se de moeda.

Leo Huberman (2014, p. 14) ressalta que as cruzadas levaram novo impulso ao comércio. A guerra pela Terra Santa, que durou do século XI ao XIV levou novo ímpeto às práticas comerciais. Milhares de europeus atravessaram o continente por terra e por mar para libertar a Terra Santa do domínio dos muçulmanos. Na medida em que necessitavam de provisões durante todo o caminho, os mercadores os acompanhavam a fim de suprir tal provimento. No retorno ao Ocidente, os cruzados traziam consigo o gosto por comidas e roupas requintadas que tinham visto e experimentado, o que criou um mercado para estes produtos. Além disso, após o século X registrou-se um acentuado aumento populacional que contribuiu para a ampliação da necessidade de produtos.

Um dos efeitos mais importantes da ampliação do comércio foi o crescimento das cidades. A expansão do comércio e o desenvolvimento das cidades conduziram a um conflito na, então, sociedade feudal. "Os senhores feudais, a princípio, não viam diferença entre suas terras na cidade e as outras que possuíam" (HUBERMAN, 2014, p. 22). Esperavam arrecadar impostos, desfrutar dos monopólios, dirigir os tribunais de justiça tal qual faziam em seus feudos. A fim de opor resistência ao poder feudal, os mercadores uniram-se em associações chamadas corporações ou ligas para conquistar para as cidades, a liberdade necessária à expansão.

A ampliação do comércio influenciou a vida dos camponeses que viviam nos feudos. Huberman (2014, p. 5) explica que com o surgimento das cidades, cresceu a necessidade de obter do campo o suprimento de alimentos e matériaprima, impulsionando a produção. Os camponeses passaram a buscar terras inexploradas a fim de aumentarem sua produção. Eram motivados pela perspectiva de liberdade que se desenhava. O comércio mostrava-se como meio possibilitador de ascensão social. 
Durante anos o camponês se havia resignado à sua sorte infeliz. Nascido num sistema de divisões sociais claramente marcadas [...] a possibilidade de se elevar acima de situações praticamente não existia, quase não tinha incentivos para fazer mais do que o necessário para sobreviver. Executava suas tarefas rotineiras de acordo com os costumes. Não havia interesse em fazer experiências com sementes ou outras formas de produzir, porque o mercado onde podia vender a produção era limitado, e muito possivelmente o senhor tomaria a parte do leão quando do aumento da colheita. Mas a situação se modificara. O mercado crescera tanto que qualquer colheita superior às necessidades do camponês e do senhor poderia ser vendida. Em troca o camponês recebia dinheiro. (HUBERMAN, 2014, p. 36).

A cidade apresentava-se ao camponês como uma oportunidade real de liberdade, vez que, com o dinheiro tornava-se possível pagar ao senhor feudal o serviço que lhe devia. O senhor feudal por sua vez estava muito interessado no dinheiro para pagar suas novas necessidades como roupas caras, agora compradas nas feiras anuais promovidas pelos mercadores nas cidades.

Os que ainda resistiam a este movimento de troca do serviço do camponês por dinheiro foram obrigados a aderir à prática com o advento da peste negra. $\mathrm{Na}$ medida em que milhares de pessoas perderam suas vidas na Europa de 1348 , o trabalho dos que sobreviveram passou a ser muito valorizado.

Um dos reflexos da emancipação dos camponeses e do crescimento das cidades foi o fortalecimento do poder do rei. Este foi um forte aliado na luta contra os senhores feudais. Pois, na medida em que estes se enfraqueciam, aumentava o poder real.

Com o tempo e o avanço da exploração do ouro e da prata o rei enriquecia. Os países que possuíam boas jazidas desses minérios e aqueles que detinham o poder sobre colônias com ricas minas conseguiam aumentar constantemente suas reservas de metais. Aqueles que não tinham a mesma sorte a solução era a balança comercial favorável. A diferença entre o valor das exportações em relação às importações era paga em metal. Tal medida impulsionou significativamente a atividade industrial. (HUBERMAN, 2014, p. 95)

Em contrapartida, como a indústria e o comércio consistiam em fonte de riqueza para o Estado, tudo que dizia respeito a tais práticas tinha a interferência real.

A indústria estava ali cerceada por uma tal rede de "pode" e "não pode" [...] que é difícil compreender como se conseguia fazer qualquer coisa. As regras e regulamentos das corporações já eram bastante prejudiciais. Continuaram 
em vigor, ou foram substituídos por outros regulamentos governamentais, ainda mais minuciosos (...) Podia o fabricante de tecidos, por exemplo, fabricar o tipo de fazenda que lhe agradasse? Não. Os tecidos tinham de ser de uma qualidade determinada e nada mais. Podia o fabricante de chapéus atrair a procura do consumidor, produzindo chapéus feitos de uma mistura de castor, pele e lã? Não. Só podia fazer chapéus todos de castor ou todos de lã, e nada mais. Podia o fabricante usar uma ferramenta nova e talvez melhor na produção de suas mercadorias? Não. As ferramentas tinham que ser de determinado tamanho e forma, e os inspetores apareciam sempre para verificar isso. (HUBERMAN, 2014, p. 109).

A política mercantilista dos monopólios significava prejuízo e destruição para o comércio livre. Além disso, o lucro obtido pela balança comercial positiva, defendida pelo mercantilismo não era distribuído em benefício da própria comunidade, "mas destinados ao próprio Estado: o exército e, sobretudo o rei e a corte" (HESSE, 2012, p. 126). A questão do comércio livre, particularmente foi defendida pelos físiocratas na França. Isso porque foi nesse país que o controle da indústria atingiu o máximo. O resultado natural desse excesso de proibições e intervenções foi um movimento igualmente profundo. "O controle demasiado da indústria estimulou a luta pela ausência total de controle" (HUBERMAN, 2014, p. 109).

Foi nesse contexto, que os fisiocratas, comerciantes contrários às políticas mercantilistas e à excessiva regulamentação à atividade industrial, forjaram a célebre frase que se tornaria o grito de batalha de todos que se opunham às restrições impostas ao comércio e à indústria: "Laissez-faire!", "Deixai fazer".

Os fisiocratas achavam que uma economia se desenvolveria melhor quando se dá rédea solta às suas forças. Estavam convencidos de que uma economia dirigida não resistia à comparação de uma economia livre. Com estas teses, foram os precursores da teoria econômica liberal clássica. (HESSE, 2012, p. 129).

Desse modo, no final do século XVIII e princípio do século XIX, ocorreu o triunfo do liberalismo clássico, base da ideologia capitalista, que teve a França como precursora de tal movimento ideológico. O Estado Liberal tinha como uma das características a defesa da livre incitava e livre concorrência e a não intervenção do Estado na esfera privada. O escocês Adam Smith, um dos principais pensadores do liberalismo, afirmava: "É suficiente que deixemos o 
homem abandonado em sua iniciativa para que ao perseguir seu próprio interesse promova o dos demais. O interesse privado é o motor da vida econômica" (SMITH, apud DERANI, 1999, p.32). Smith deu forma ao conceito da mão invisível, pelo qual o mercado sempre irá reinstaurar o equilíbrio entre todos os agentes econômicos, de modo a não se colocarem restrições à liberdade.

Diante desse contexto histórico, a livre-iniciativa apresenta-se como uma das facetas do livre comércio, garantindo o livre exercício de atividade econômica, desde que esta seja lícita. Em razão do princípio da livre-iniciativa, os agentes econômicos agem de maneira livre, sem intervenção direta do Estado. Segundo Tarcísio Teixeira (2013, p.43): “[...] a isso se denomina também economia de mercado, em que a maior parte da atividade econômica é gerada pela iniciativa privada, ficando o poder público com a função de regulamentar e fiscalizar".

Inúmeros sentidos podem ser extraídos da liberdade de iniciativa econômica. Exemplos são: liberdade de comércio e indústria, do qual advém a faculdade de criar e explorar atividade econômica, e a liberdade de concorrência, que se traduz na faculdade de conquistar clientela, desde que não por intermédio de concorrência desleal.

A introdução dos ideais liberais no contexto econômico e social acarretou em consequências para o Direito, pois este, enquanto fato social, "[...] não existe senão na sociedade e não pode ser concebido fora dela." (REALE, 2003, p. 2) Assim, é a partir da realidade posta que o direito desenha-se. Embora o direito exista desde os mais remotos tempos, as correntes do contratualismo e do iluminismo, surgidas com o Estado liberal, no final do século XVIII conduziram ao Estado constitucional, entendido como Estado assentado em uma Constituição fundadora e reguladora tanto de toda sua organização como da relação com os cidadãos e tendente à limitação do poder. Assentado na ideia de liberdade e, em nome dela, o Estado liberal empenhou-se em limitar o poder político, tanto internamente quanto externamente. As transformações registradas não ficaram restritas ao campo da política, as revoluções liberais derrubaram velhos hábitos. Alguns valores perderam-se enquanto outros foram adquiridos. Houve um realce das liberdades jurídicas do indivíduo, como a liberdade contratual e a absolutização da propriedade privada. As Constituições da época, entre as quais as brasileiras de 1824 e de 1891 refletem esta tendência. Por osmose ou por imitação, os regimes liberais foram-se implantando ao longo da primeira metade do século XIX. (MIRANDA, 2011, p. 32-35)

O parágrafo 17 do artigo 72 da Constituição de 1891 dispunha que "[...] o direito de propriedade mantem-se em toda sua plenitude". A livre iniciativa 
consiste em corolário do princípio absoluto do direito de propriedade. (FONSECA, 2010, p. 189).

Naquele momento histórico, o Estado não deveria intervir na atividade econômica a não ser como garantidor da liberdade de mercado e dos direitos individuais. Cabia à iniciativa privada a escolha da maneira como conduziria seus negócios e buscaria seus objetivos.

Contudo esta falta de mecanismos de controle das atividades econômicas gerou consequências. As empresas que, por diversas razões, conseguiam se sobressair economicamente, detinham maiores condições de absorver os avanços tecnológicos que surgiam. A concorrência tornou-se tão agressiva e destrutiva que, em pouco tempo, as empresas menores foram eliminadas. Os concorrentes mais poderosos, em vias de se destruírem uns aos outros, frequentemente optavam por associar-se, fundindo-se para assegurar sua sobrevivência levando a concentração de capital que mostrou seus efeitos controversos. (HUNT; SHERMAN, 2013, p.120)

A concepção de um liberalismo atomista, de liberdade do indivíduo no âmbito do mercado, veio a ser desmentida pela realidade histórica. A partir de meados do século XIX o capitalismo se transforma. As unidades se unem, formando grupos, dando origens ao novo Estado industrial. Com os grupos econômicos surgem os primeiros questionamentos sobre a plena liberdade do comércio. A crise se instaura e provoca, no período entre as duas grandes guerras, o surgimento de um novo Direito e a imperiosidade da atuação do Estado no domínio econômico. (FONSECA, 2010, p. 190).

Os economistas neoclássicos de segunda e terceira geração foram forçados a admitir que existiam imperfeições no modelo proposto pelos clássicos liberalistas, de que o mercado, totalmente livre, se autorregularia e traria somente benefícios à sociedade. Embora convictos dos aspectos positivos do sistema capitalista, os neoclássicos de segunda e terceira geração propuseram algumas correções a tal sistema, como a intervenção governamental.

A concentração do poder econômico nas mãos das grandes corporações e o consequente desaparecimento de pequenas empresas que ficaram impossibilitadas de concorrer com os grandes grupos desencadeou a necessidade de o Estado intervir para sanar a crise do liberalismo econômico, protegendo as classes que poderiam vir a ser desfavorecidas com a nova feição das empresas.

O controle do poder econômico pelo Direito (...), e consequentemente o combate ao seu uso abusivo, importa em dois elementos essenciais: a 
regulação e a concorrência. Existe, entretanto, uma linha bastante tênue entre regulação e concorrência, sobretudo em épocas de concentração do poder econômico, fazendo-se necessária uma regulação mais atuante e comprometida com o valor institucional concorrência (BAGNOLI, 2009, p.71)

O objetivo do Estado não era impedir a concentração de empresas, mas garantir efetivamente a liberdade de mercado. Assim, além de buscar assegurar a liberdade de iniciativa e a livre concorrência que eram ameaçadas pelo agigantamento de algumas corporações, objetivava também defender o interesse da coletividade.

A Constituição brasileira de 1934 aderiu ao novo discurso, introduzindo, pela primeira vez, um título configurador da nova postura do Estado dentro da ordem liberal. "O ingresso do Estado para atuar no mercado gera uma nova ordem a ser disciplinada, a Ordem Econômica e Social” (FONSECA, 2010, p. 193).

Mas, foi na Constituição brasileira de 1937 que pela primeira vez utilizouse a expressão "intervenção do Estado no domínio econômico". A Constituição de 1946 explicitou os parâmetros fundamentais que balizariam a intervenção do Estado sobre o domínio econômico. Fixando em seu artigo 145, os pilares da ordem econômica liberal que se instaurara.

Nesse contexto histórico, de imposição de balizas à racionalidade econômica e proteção aos interesses da coletividade em face do excessivo aumento do poder econômico das grandes empresas, a Constituição de 1967 com a emenda n. 1/69 positivou a defesa do consumidor.

\section{DA REVOLUÇÃO INDUSTRIAL À PROTEÇÃO DO CONSUMIDOR}

A evolução histórica que culminou com o liberalismo econômico está intrinsecamente ligada à mudança da relação do homem com o capital e o comércio. O princípio basilar do liberalismo clássico, o direito absoluto à propriedade privada, direcionava as ações humanas inexoravelmente à acumulação do capital. O comércio apresentava-se como meio mais eficiente à expansão desse capital. As empresas detinham uma única preocupação, o lucro a qualquer preço.

Paralelamente à sedimentação do liberalismo econômico, um importante fenômeno era consolidado no continente europeu, a Revolução Industrial. 
No século XVIII, a Inglaterra já dispunha de um mercado bem desenvolvido. O capitalismo seguia como sistema econômico cada vez mais fortalecido. A produção de bens manufaturados em quantidades cada vez maiores e redução dos custos de produção possibilitaram a obtenção de lucros consideráveis. $\mathrm{O}$ interesse em ampliar a margem de lucros, combinado com o crescimento da exportação de produtos manufaturados, provocou uma verdadeira explosão de inovações tecnológicas no final do século XVIII e princípio do século XIX, das quais a mais importante foi o desenvolvimento da máquina a vapor. Ao contrário da energia hidráulica, que requeria proximidade dos cursos d'água, a energia a vapor livrou as indústrias das imposições geográficas. Onde fosse possível adquirir carvão mineral a um preço razoável, instalava-se uma máquina a vapor. (HUNT; SHERMAN, 2013, p.62).

As principais cidades manufatureiras tiveram um crescimento espetacular. A população de Manchester, por exemplo, estimada em 17.000 habitantes em 1760, subiu para 237.000 habitantes em 1831 e 400.000 em 1851. A produção de bens manufaturados praticamente dobrou na segunda metade do século XVIII, e cresceu a um ritmo ainda mais intenso no princípio do XIX. Por volta de 1801 , cerca de $30 \%$ da força de trabalho existente na Inglaterra estava empregada nas atividades manufatureiras e mineradoras; em 1831, esta cifra ascendeu para cerca de 40\%. (HUNT; SHERMAN, 2013, p. 62).

Assim, o liberalismo econômico e a revolução industrial consistiam em poderoso combustível a serviço do crescimento econômico das empresas.

Com a substituição da manufatura pela máquina, teve início a produção em massa. A necessidade de os empresários escoarem sua produção, aliada à baixa intervenção estatal na ordem econômica, resultaram em uma série de atos abusivos praticados em detrimento da coletividade.

Também o modo de distribuição foi modificado. Se antes era o próprio fabricante que se encarregava de distribuir seus produtos, dominando todo o processo produtivo, a partir de certo momento a distribuição também passou a ser em massa, em cadeia, em grande quantidade, por mega-atacadistas, fazendo com que comerciantes e consumidores passassem a receber os produtos fechados, lacrados e embalados, sem condições de conhecerem seu real conteúdo.

Esses novos mecanismos de produção e distribuição corporificaram inéditos instrumentos jurídicos tais como os contratos coletivos, contratos de massa, contratos por adesão, cujas cláusulas gerais são preestabelecidas unilateralmente pelo fornecedor sem qualquer participação do consumidor. $\mathrm{O}$ que amplificava sua posição de hipossuficiência e vulnerabilidade. 
O surgimento dos grupos econômicos e das grandes corporações contribuiu, ainda mais, para o aumento do desequilíbrio entre os dois lados das relações de comércio, empresa e consumidor. O Estado passou a intervir no domínio econômico a fim de proteger os interesses coletivos e dentre estes os direitos do consumidor. A intervenção do Estado sobre o domínio econômico mostrou-se instrumento imprescindível para manutenção da livre-iniciativa e da livre-concorrência.

Após longa atuação jurisprudencial, foram editadas, em diversos países do mundo, leis específicas para disciplinar as relações de consumo.

No Brasil, entre as décadas de 40 e 60 o direito do consumidor começou a surgir quando foram sancionadas diversas leis e decretos federais legislando sobre saúde, proteção econômica e comunicações. Dentre as quais, pode-se citar: a Lei n. 1221/51, denominada Lei de Economia Popular; a Lei Delegada n. 4/62; a Constituição de 1967 com a emenda n. 1/69, que consagrou a defesa do consumidor.

Mas foi a Constituição Federal de 1988 que sedimentou a defesa do consumidor como um valor a ser observado pela ordem econômica. Isso pode ser percebido tanto no inciso $\mathrm{V}$ do artigo 170, quanto no inciso XXXII do artigo $5^{\circ}$ da $\mathrm{CF}$, o qual prevê que "o Estado promoverá, na forma da lei, a defesa do consumidor". Figurando, portanto, como direito fundamental expresso.

Em 1990 surge a Lei Federal 8078/90, o Código de Defesa do Consumidor. O CDC regula não só relações privadas como também atinge o interesse de toda a coletividade, vez que limita a autonomia da vontade das partes. Tratamse de normas públicas de caráter cogente, o que significa dizer que a ninguém é dada a possibilidade, ainda que por acordo, de afastar sua aplicabilidade.

\section{LIVRE-INICIATIVA E A PROTEÇÃO DO CONSUMIDOR NA CONSTITUIÇÃO FEDERAL DE 1988}

Segundo Fernando Aguillar (2012, p. 264), no sistema de livre mercado, base do modo de produção capitalista, os empresários privados têm o papel de liderança no desempenho das atividades econômicas. Tal fato recebe respaldo legal e constitucional no mundo jurídico. Para o autor, podem-se dividir em dois grandes grupos as normas jurídicas que tutelam o funcionamento do mercado capitalista: normas estruturais e normas de ajuste. As primeiras dizem respeito àquelas que estabelecem a estrutura de base do mercado como, por exemplo, as que instituem a primazia da iniciativa privada em face do Estado empresário 
e as que consagram o princípio da livre-iniciativa. As segundas intervêm sobre o funcionamento do mercado instituído, a fim de que determinados resultados sejam alcançados, reprimidos ou estimulados.

Em consonância com a definição de um regime econômico de inspiração neoliberal, pela Constituição, o legislador ordinário estabeleceu mecanismos de proteção à liberdade de competição e de iniciativa visando coibir a infração à ordem econômica e a concorrência desleal (COELHO, 2011, p. 46).

O artigo 170 da Constituição Federal de 1988 ao dispor sobre a ordem econômica deixa clara a existência destas duas ordens normativas. No caput preceitua que a ordem econômica será fundada na livre iniciativa e logo adiante elenca um rol de princípios que deverão ser observados por esta mesma ordem econômica.

Embora a livre-iniciativa constitua desdobramento do direito fundamental à liberdade, a mesma não pode ser interpretada restritivamente à liberdade econômica. A livre-iniciativa não se resume a "princípio básico do liberalismo econômico" ou a "liberdade de desenvolvimento da empresa", enquanto fundamento constitucional não deve ser vista sob uma ótica individualista, mas sim no quanto expressa algo socialmente valioso. (GRAU, 2004, p. 186)

A liberdade é um atributo inalienável do homem, desde que seja concebida dentro de um todo social e não exclusivamente em sua individualidade. E Grau pontua que o termo homem aqui apontado deve referir-se ao homem social, associado ao homem e não o homem inimigo do homem. (GRAU, 2004, p. 191).

A Constituição Federal de 1988 bem denota esta preocupação com as duas faces da relação de consumo. $\mathrm{O}$ artigo $1^{\circ}$ da Constituição Federal em seu inciso IV tenha alçou a livre-iniciativa a fundamento do Estado Democrático de Direito. O artigo $5^{\circ}$, inciso XXXII, por sua vez, expressa que "o Estado promoverá na forma da lei, a defesa do consumidor". Alçando a proteção do consumidor a princípio fundamental do ordenamento jurídico brasileiro. Ademais, o legislador originário deixa clara sua preocupação ao definir no artigo $3^{\circ}$, inciso I, como um dos objetivos fundamentais da República Federativa do Brasil a construção de uma sociedade livre, justa e solidária.

Realizando-se uma breve análise sobre tais termos tem-se que sociedade livre é aquela que busca a efetivação da liberdade real ou material e não somente a liberdade formal. Sociedade justa é aquela que realiza justiça social. E solidária é a sociedade que não inimiza os homens entre si, fraternizando e não afastando os homens uns dos outros. 
Resta claro, portanto que ainda que o Estado brasileiro entenda que a racionalidade econômica deve usufruir de liberdade para iniciar e gerir suas atividades sem intervenção direta sobre estas, tal liberdade não constitui, de forma alguma, princípio absoluto, dispondo a ordem econômica que contribua em assegurar a todos existência digna conforme os ditames da justiça social, observando vários princípios, dentre os quais a defesa do consumidor.

\section{4 ÉTICA EMPRESARIAL: UMA NOVA VISÃO ACERCA DO CONSUMIDOR}

Se em um primeiro momento a proteção ao consumidor apresentou-se como ônus imposto pelo Estado à racionalidade econômica a fim de equilibrar as relações de consumo, contemporaneamente tais relações têm adquirido novos contornos.

Segundo Guido Alpa (1986, p.9) não é possível tratar de tutela do consumidor sem envolver a questão do controle da atividade empresarial. Tutela do consumidor e controle da iniciativa econômica privada são aspectos do mesmo fenômeno.

Após o advento da Constituição Federal de 1988 e do Código de Defesa do Consumidor em 1990, não se pode mais conceber a atividade empresarial desvinculada de uma preocupação efetiva com sua conduta ética perante o consumidor a partir dos princípios e regras estabelecidos tanto na primeira como no segundo. (LUCCA, 2009, p. 362).

O consumidor, desde que as práticas consumistas existem no seio da humanidade, sempre foi parte fundamental das relações de consumo. Obviamente, não há como se falar em consumo sem que exista a figura do cliente. Empresa e consumidor constituem lados opostos de uma mesma relação. De um lado, as empresas viabilizam a subsistência material e intelectual dos consumidores, por outro, estes consistem em parte fundamental para o crescimento econômico das empresas sem os quais as relações comerciais não existiriam.

Todavia, tal relação adquiriu diferentes contornos ao longo da história.

$\mathrm{Na}$ Europa medieval, a ideologia que proporcionou o alicerce moral, capaz de manter coesa a Europa feudal, denominada ética de corporação cristã ou ética paternalista cristã, pregava a visão de que a sociedade consistia em entidade única na qual os homens que ocupavam posição econômica superior tinham obrigações paternalistas para com os homens comuns, isto é, os pobres. Os 
escritos de Clemente de Alexandria previam que os homens ricos tinham uma obrigação especial: deviam encarar as suas riquezas como dádivas de Deus, e utilizá-las com discernimento, em proveito do bem-estar de seus semelhantes. (HUNT; SHERMAN, 2013, p.17).

Em um momento posterior, tal visão foi substituída pela apologia ao individualismo pregada pela filosofia liberal clássica.

Nas palavras de Adam Smith, cada produtor:

[...] tem em vista exclusivamente sua própria segurança: ao dirigir a indústria de modo a que os bens produzidos alcancem o maior valor possível. (...) Ao perseguir seu próprio interesse, frequentemente promove o interesse da sociedade de forma mais eficaz do que quando é realmente sua intenção promovê-lo. Eu nunca soube de grandes ações praticadas por aqueles que se dedicam ao comércio em nome do bem comum. Em verdade, esse é um sentimento raro entre os mercadores, e bastariam poucas palavras para dissuadi-los de causa tão nobre. (SMITH apud HUNT; SHERMAN, 2013, p. 69).

Por um longo período, o único enfoque das empresas foi a obtenção do lucro e o consumidor era visto em uma visão utilitarista como um instrumento viabilizador deste lucro.

A intervenção do Estado sobre o domínio econômico trouxe a necessidade às empresas de incluírem no rol de suas ações, princípios que por vezes não coincidiam com seu telos natural. O artigo 170 da Constituição Federal e seus incisos bem denotam tal tendência.

Contudo, a contemporaneidade tem trazido à baila uma nova visão acerca da relação empresa com a sociedade, aqui tratada na figura do consumidor.

Uma interseção de princípios e valores que pode ser vislumbrada em relação aos princípios norteadores das condutas das empresas contemporâneas. A inclusão da ética empresarial aos objetivos das empresas configura exemplo disso. Segundo Domingo García Marzá (2008, p.14) qualquer empresa não pode ser tratada como se fosse negócio de uma pessoa ou de um grupo restrito, pois seu papel é essencialmente social e, por isso, ela deve assumir este ônus de compromisso moral e responsabilidade social.

Se em um primeiro momento o consumidor era visto pelas empresas como instrumento a serviço da consecução do lucro, contemporaneamente, tais empresas paulatinamente percebem a necessidade em estabelecer com 
seus consumidores uma relação de confiança. Ser uma empresa ética e obter lucro já não constituem conceitos antagônicos.

Hoje, já não surpreende mais identificar os dois conceitos, até há bem pouco tempo antagônicos, juntos. Na verdade, afirmações como negócio é negócio definiam um contexto no qual ser ético significava, em última análise perder dinheiro. A empresa era entendida como algo objetivo, com uma lógica clara e uma finalidade concreta, voltada ao lucro econômico. Dessa forma, gerar valor significava produzir valor econômico, um tanto adverso à ética, sempre representada como algo subjetivo, próprio da consciência de cada um, centrada naquilo que pode ser modificado a partir da vontade individual de cada um. [...] Essa divisão de tarefas não corresponde às expectativas sociais atualmente depositadas na empresa. (...) em prestigiosas listas da Fortune, por exemplo, o primeiro fator que mais influi na reputação de uma companhia é o seu desempenho financeiro, enquanto que o segundo é o seu comportamento ético. (MARZÁ, 2008, p. 24).

A globalização potencializou a importância da confiança nas relações entre empresa e consumidor. Segundo Garcia Marzá (2008, p.32), a globalização não implica um desaparecimento do Estado e de suas funções econômicas, mas um recuo na visão de que este consiste em único responsável pelo âmbito público. Há um reconhecimento pela sociedade civil de que existem outros agentes, individuais e institucionais que também devem ocupar-se do bemcomum, gerando um aumento de responsabilidades dos atores que compõem a sociedade.

Os avanços tecnológicos aplicados aos meios de comunicação facilitaram a comunicação de pessoas localizadas nas mais diferentes localidades do globo. A comunicação digital ultrapassou em alcance e capacidade todas as demais mídias, propiciando que um grande número de pessoas possa ter acesso e compartilhar múltiplas informações e trocá-las em um mesmo tempo, independentemente das distâncias.

Este novo contexto na seara da comunicação propiciou a existência de uma opinião pública mundial, para qual "a confiança adquire um ativo cada vez mais importante para o desenvolvimento da empresa" $\mathrm{O}$ atual processo de globalização permite que se faça um julgamento do bom e do mau desempenho da empresa com alcance global e que seja denunciado o não-cumprimento de expectativas em determinado espaço geográfico em que ocorram. (MARZÁ, 2008, p. 64). 
O consumidor passa a esperar uma maior e melhor contribuição das empresas ao desenvolvimento econômico, social e ecológico.

A confiança constitui premissa básica em quaisquer tipos de interações, desde as relações pessoais mais elementares até as mais complicadas redes institucionalizadas. No âmbito empresarial, contemporaneamente, a confiança passa a compor o capital intangível das empresas.

No contexto globalizado, o comprometimento das empresas com práticas que respeitem direitos assegurados aos consumidores, aos trabalhadores, ao meio ambiente, dentre outros, tornam-se ações valorizadas e alimentadoras da confiança que os consumidores depositam nas empresas com as quais se relacionam. A reputação da empresa passa a ser cada vez mais um capital intangível que repercute na aceitação de um produto ou marca. Nesse sentido, dispõe Garcia Marzá (2008, p.34):

Se o âmbito de ação da empresa é, em grande parte global, também o são as justificativas com as quais, de fato, ajuizamos a justiça dessas ações. Em função disso, exigimos responsabilidades e estamos convencidos de uma boa reputação ou, senão, retiramos a confiança depositada em um produto ou marca.

Diante de tal contexto, a ética empresaria apresenta-se como o instrumento possibilitador de construir a confiança que uma determinada empresa irá gerar em seus consumidores e na sociedade. Fazendo com que estes assumam importante papel na internalização da ética empresarial nas condutas das empresas.

[...] a tarefa primordial da ética empresarial consiste em ocupar-se das condições de possibilidade da credibilidade social da empresa e, portanto, da confiança nela depositada por parte de todos aqueles grupos que formam parte ou estão relacionados por sua atividade (MARZÁ, 2008, p.27).

Assim, a questão da livre iniciativa em relação à proteção ao consumidor em muito se modificou ao longo da história. A desvinculação de tais conceitos, próprios do liberalismo clássico passou à inserção da confiança estabelecida entre empresa e consumidor ao capital intangível das empresas. Tal evolução atesta a tendência iniciada no pós-guerra de conduzir o homem ao centro das relações sociais e econômicas, a fim de que a dignidade da pessoa humana passe a ser um valor cada vez mais internalizado pela racionalidade econômica na sociedade contemporânea. 


\section{CONSIDERAÇÕES FINAIS}

Empresa e consumidor constituem dois lados de uma mesma relação. Apesar de figurarem em posições opostas formam um vínculo de complementariedade. De um lado, as empresas viabilizam a subsistência material e muitas vezes imaterial dos consumidores, por outro, estes consistem em parte fundamental para o crescimento econômico das empresas sem os quais as relações comerciais não existiriam.

Embora, o elo entre empresa, anteriormente representada pela figura dos comerciantes, e consumidor sempre tenha existido, tal relação adquiriu diferentes contornos ao longo da história. Partindo da sociedade feudal, na qual as práticas comerciais se davam de forma rudimentar, passando pelo mercantilismo, onde as riquezas frutos da expansão do comércio eram monopolizadas pelo poder real até o liberalismo clássico, no qual não era possível identificar uma real preocupação dos comerciantes em relação consumidores. Estes constituíam apenas um elemento fundamental na geração do lucro almejado pelo comerciante e posteriormente pela empresa. Principalmente no liberalismo, quando ficou expressa a filosofia de que era através da liberdade concedida à esfera econômica que se alcançaria o bem de todos.

Historicamente, tal teoria denotou suas falhas. A liberdade plena, defendida pelo liberalismo clássico acarretou em forte concentração de renda culminando na fusão das empresas mais fortes e no desaparecimento das que não dispunham de instrumentos para permanecer no mercado.

A intervenção do Estado sobre o domínio econômico mostrou-se como instrumento imprescindível para manutenção da livre-iniciativa e da livreconcorrência.

Neste contexto surgiram nos ordenamentos princípios sociais que deveriam ser incorporados às condutas da ordem econômica, entre eles a proteção ao consumidor.

O que inicialmente foi internalizado pela racionalidade econômica como um ônus, adquiriu nova dimensão. A confiança gerada pela empresa no consumidor, contemporaneamente foi alçada a parte do capital intangível da empresa.

A globalização com seus avanços tecnológicos, em especial nos meios de comunicação possibilitou a existência de uma opinião pública mundial, para qual a confiança adquire um ativo cada vez mais importante para o desenvolvimento da empresa. Contemporaneamente, é possível a construção 
de um julgamento do bom e do mau desempenho da empresa com alcance global, sendo denunciadas as condutas que não correspondam às expectativas da sociedade. A ética empresarial apresenta-se como o instrumento possibilitador de construir esta confiança.

Embora a globalização não implique no desaparecimento do Estado e de suas funções econômicas, este não constitui o único responsável pelo âmbito público. Há um reconhecimento pela sociedade civil de que existem outros agentes, individuais e institucionais que também devem ocupar-se do bemcomum, gerando um aumento de responsabilidades dos atores que compõem a sociedade.

Desse modo, através da confiança que as empresas pretendem estabelecer nas relações de consumo, o consumidor, ainda que indiretamente, assume importante papel no fomento de atitudes éticas e implementadoras do bem comum por parte das empresas na sociedade contemporânea.

\section{REFERÊNCIAS}

AGUILLAR, Fernando Herren. Direito Econômico. Do direito nacional ao supranacional. São Paulo: Atlas, 2012.

ALPA, Guido. Diritto privato dei consumi. Bolonha, Itália: Società Editrice II Mulino, 1986.

BAGNOLI, Vicente. Direito e poder econômico. Rio de Janeiro: Elsevier, 2009.

COELHO, Fábio Ulhoa. Manual de Direito Comercial. São Paulo: Saraiva, 2011.

DERANI, Cristiane. Política Nacional das Relações de Consumo e o Código de Defesa do Consumidor. Revista de Direito do Consumidor, n. 29, p. 29-39, jan./mar., 1999.

FONSECA, João Bosco Leopoldino. Direito Econômico. Rio de Janeiro: Forense, 2010.

GRAU, Eros Roberto. A ordem econômica na Constituição de 1988. São Paulo: Malheiros, 2004. 
HESSE, Helge. A história do mundo em 50 frases. Rio de Janeiro: Casa da Palavra, 2012.

HUBERMAN, Leo. História da Riqueza do Homem. Rio de Janeiro: LTC, 2014.

HUNT, E. K.; SHERMAN, H. J. História do Pensamento Econômico. Petrópolis: Vozes, 2013.

LUCCA, Newton de. Da Ética Geral à Ética Empresarial. São Paulo: Quartier Latin, 2009.

MARZÁ, Domingos García. Ética Empresarial. Do diálogo à confiança na empresa. São Leopoldo: Unisinos, 2008.

MIRANDA, Jorge. Teoria do Estado e da Constituição. Rio de Janeiro: Forense, 2011.

REALE, Miguel. Lições Preliminares de Direito. São Paulo: Saraiva, 2003.

TEIXEIRA, Tarcísio. Direito empresarial sistematizado. Doutrina e prática. São Paulo: Saraiva, 2013.

Submetido em 09/03/2015 Aprovado em 27/05/2015

Como citar: MUNIZ, Tânia Lobo; TORRES, Glaucia Cardoso Teixeira. Da livre iniciativa e da confiança na relação empresa e consumidor. Scientia Iuris, Londrina, v.19, n.1, p.167-184, jun. 2015. 